\title{
Quantitation of Sitagliptin in Drug Product by Validated Reversed Phase Liquid Chromatographic Technique
}

\section{Sharifa Sultana ${ }^{1,2}$, Md. Shahadat Hossain ${ }^{1}$, Md. Samiul Islam ${ }^{1}$ and Abu Shara Shamsur Rouf ${ }^{1}$}

\author{
${ }^{1}$ Department of Pharmaceutical Technology, Faculty of Pharmacy, University of Dhaka \\ Dhaka-1000, Bangladesh \\ ${ }^{2}$ Department of Pharmacy, Faculty of Allied Health Sciences, Daffodil International University \\ Dhaka-1207, Bangladesh
}

(Received: 3 April, 2018; Accepted: 20 May, 2018; Published (web): 10 June, 2018)

\begin{abstract}
A novel reversed phase ultra-high performance liquid chromatographic (RP-UHPLC) method was developed for the estimation of sitagliptin in pharmaceutical dosage form. Separation was done by a X-bridge $\mathrm{C}_{18}$ column (4.6 i.d. $\times 150 \mathrm{~mm}, 5 \mu \mathrm{m}$ particle size) with a flow rate of $1 \mathrm{ml} / \mathrm{min}$ using phosphate buffer (pH 6) and acetonitrile $(70: 30, \mathrm{v} / \mathrm{v})$ as mobile phase at $268 \mathrm{~nm}$ using photodiode array plus (PDA+) detector. The retention time was found at $4.607 \mathrm{~min}$. The developed method was validated as per the requirements of ICH-Q2B guidelines for specificity, system suitability, linearity, precision, accuracy, sensitivity and robustness. The linear regression analysis data for the linearity plot showed correlation coefficient values of 0.999 with LOD value of $0.06 \mu \mathrm{g} / \mathrm{ml}$ and LOQ of $0.225 \mu \mathrm{g} / \mathrm{ml}$. The relative standard deviation (\%RSD) for inter-day and intra- day precision was not more than $2.0 \%$. The method was found to be accurate with percentages recovery of $98.50 \pm 0.03$ to $99.70 \pm 0.05$ and the \% RSD was less than 2 . The results showed that the proposed method is highly convenient for routine analysis of sitagliptin.
\end{abstract}

Key words: Sitagliptin, UHPLC, validation.

\section{INTRODUCTION}

Sitagliptin, chemically [(R)-4-oxo-4-[3-(triflouromethyl)-5,6-dihydro[1,2,4]triazolo[4,3-a] pyrizine-7(8H)-yl]-1- (2,4,5-trifloro phenyl)butan-2amine] (Figure 1), is a long-acting pyrizine-based drug. It is one of the promising drugs used for the treatment of type II diabetes. ${ }^{1,2}$

Since the inception in 2006 as first dipeptidyl peptidase-4 (DPP-4) inhibitor, it is a well-known hypoglycemic drug concurrently administered with lifestyle changes. ${ }^{3}$ By enhancing the effect of incretins, it reduces blood glucose concentration and finally causes significant increase in insulin secretion. According to the global report on diabetes in 2014,

Correspondence to: Abu Shara Shamsur Rouf Email: rouf321@yahoo.com

Dhaka Univ. J. Pharm. Sci. 17(1): 123-129, 2018 (June)

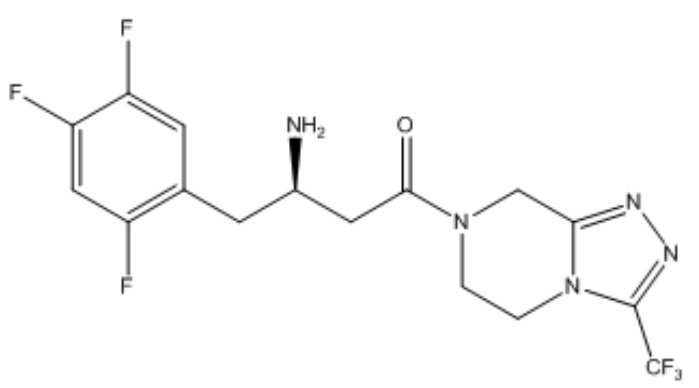

Figure 1. Structure of sitagliptin.

422 million adults were living with diabetes globally, compared to 108 million in $1980 .{ }^{4}$ So, the demand of antidiabetic drugs especially DPP-4 inhibiting drugs have been rising in pharmaceutical market day by day. ${ }^{5}$ To ensure the quality of the drug products in a cost effective way, it is helpful to use a fast, precise, sensitive, and robust HPLC method for the quantitation of sitagliptin. In continuation of our research work in the field of analysis of food and 
drug products e.g. Sultana et $a .^{6-8}$, Alam et al. ${ }^{9}$, Hossain et al. ${ }^{10}$, Islam et al. ${ }^{11}$, Hossain et al. ${ }^{12}$, here, we report a simple, robust, economic and validated method for the estimation of sitagliptin.

Literature review revealed the determination of sitagliptin in dosage form either alone or combined form by UV spectrophotometry ${ }^{13-15}$, RP-HPLC ${ }^{5,16-21}$, $\mathrm{UPLC}^{22}$, tandem mass spectrometry ${ }^{23,24}$ and capillary electrophoresis. ${ }^{25}$ However, UV spectrophotometry is the simplest technique but it is deficient in accuracy and precision and needs relatively higher amount of analytes for detection. HPLC is the best option for analysis because of its simplicity and sensitivity. Most of the reported methods for the estimation of sitagliptin contained complex mixture in mobile phase ${ }^{5,16}$, higher percentages of organic solvent in mobile phase $\mathrm{e}^{15,19,20}$ and relatively long retention time. $^{17,18,22}$ Therefore, we aimed to establish a validated cost-effective, simple, fast and precise UHPLC method to determine sitagliptin in oral tablet dosage form.

\section{MATERIALS AND METHODS}

Chemicals and reagents. Sitagliptin standards (purity $>99.87 \%$; Aurobindo Pharma, Hyderabad, India) were obtained from Incepta Pharmaceutical Ltd. Bangladesh as a generous gift sample for research. HPLC-grade acetonitrile was obtained from RCI Labscan, Thailand, analytical potassium dihydrogen phosphate was obtained from Daejung Chemicals \& Metal Co. Ltd., Korea and nano pure water was obtained from Evoqua Water Technologies. All other chemicals used were of analytical grade. Gilipta 50 tablet manufactured by Beximco Pharmaceuticals Ltd. Bangladesh was purchased from the local pharmaceutical market.

Instrumentation. Perkin Elmer Flexar series (FX-15 binary pump, PDA plus detector, autosampler, vacuum degasser and column oven) with Chromera Manager Software was used for analysis in reverse phase ultra-high performance liquid chromatography (RP-UHPLC) system. The isocratic elution was done with the mobile phase consisting of mixture of phosphate buffer at $\mathrm{pH} 6.0$ and acetonitrile (70:30, v/v) (Table 1). The mobile phase was degassed in an ultrasonic bath (Human Lab Instrument Co. Ltd., Korea) and then filtered through $0.45-\mu \mathrm{m}, 47 \mathrm{~mm}$ nylon membrane filter (Restek, USA).

Table 1. Chromatographic conditions.

\begin{tabular}{ll}
\hline Equipment & UHPLC with PDA+ Detector \\
\hline Column & $\begin{array}{l}\text { X-bridge } \mathrm{C}_{18}(4.6 \text { i.d. } \times 150 \mathrm{~mm}, 5 \mu \mathrm{m} \\
\text { particle size })\end{array}$ \\
Flow rate & $1.0 \mathrm{ml}$ per min \\
Wavelength & $268 \mathrm{~nm}$ \\
Injection volume & $20 \mu \mathrm{L}$ \\
Column temperature & $25^{\circ} \mathrm{C}$ \\
Run time & $10 \mathrm{~min}$ \\
\hline
\end{tabular}

Preparation of standard solution. Stock solution with a concentration of $1 \mathrm{mg} / \mathrm{ml}$ of sitagliptin was prepared in mobile phase. A working standard solution with a concentration of $50 \mu \mathrm{g} / \mathrm{ml}$ was prepared by suitable dilution with mobile phase from the stock solution.

Preparation of sample solution. Glipita 50 tablets were crushed into fine powder. By transferring a weighed amount of the powder, stock sample solution was prepared with a concentration of $1 \mathrm{mg} / \mathrm{ml}$ by mobile phase which was equivalent to $100 \mathrm{mg}$ sitagliptin in a $100 \mathrm{ml}$ volumetric flask. 50 $\mathrm{ml}$ mobile phase was added to the sample and sonicated for $10 \mathrm{~min}$. Finally, the volume was adjusted with mobile phase up to the mark. Then the solution was filtered (Whatman filter paper, Grade 1, $110 \mathrm{~mm}$ diameter). For further use the solution was stored in suitable container. A sample solution of 50 $\mu \mathrm{g} / \mathrm{ml}$ was prepared for assay of tablet from the stock solution by dilution with the mobile phase and then filtered through $0.22 \mu \mathrm{m}$ disc filter (Filter-Bio).

Method validation. The developed method for the determination and validation of sitagliptin was carried out as per ICH guidelines. ${ }^{26}$

Specificity. Separate injection of blank, standard and sample solution of sitagliptin in triplicate was used for the determination of specificity. By the value of peak purity, the results were confirmed (Figure 2). 
System suitability test. By injecting six replicate injections of standard solution $(50 \mu \mathrm{g} / \mathrm{ml})$ system suitability was established. The relative standard deviation (\% RSD) and mean tailing factor of responses were calculated.

Linearity. Different concentrations of sitagliptin $(10,20,30,40$ and $50 \mu \mathrm{g} / \mathrm{ml})$ were prepared by suitable dilutions of standard stock solution to check the linearity of the developed method. The limit of detection (LOD) was determined at the signal to noise ratio of 3:1 and limit of quantitation (LOQ) was determined at the signal to noise ratio 10:1.

Precision. Precision was assessed by intermediate precision and repeatability or intra-assay precision. Repeatability was determined from six replicate injections of $20 \mu \mathrm{l}$ each of nominal standard solution $(50 \mu \mathrm{g} / \mathrm{ml})$. The nominal standard solution was analyzed for a period of six days with six replicate injections of $20 \mu \mathrm{l}$ each on daily basis. The results of both studies were compared (intermediate precision) and expressed as \%RSD of the measurements.

Accuracy. To check for accuracy or recovery of the developed method as well as studying the interference of formulation additives on analysis the standard drug substance was spiked with the sample solution at $80 \%, 100 \%$ and $120 \%$. Triplicate injections were carried out for all determinations.

Robustness. By insignificant variations of the technique robustness study of the method was carried out such as altering flow rate, column temperature and changes in composition of the mobile phase.

\section{RESULTS AND DISCUSSION}

\section{Optimization of chromatographic condition.}

During method development, different chromatographic conditions were used to achieve good separation of sitagliptin. Several columns $\left(C_{8}\right.$ and $\mathrm{C}_{18}$ ) and columns lengths (150 and $250 \mathrm{~mm}$ ), various mobile phase components including (methanol, acetonitrile, phosphate buffer and water), different $\mathrm{pH}$ levels (between 3 and 7) and flow rates $(0.5-2 \mathrm{ml} / \mathrm{min})$ were tried. Finally, it was found better to use the $\mathrm{C}_{18}$ column (4.6 i.d. $\times 150 \mathrm{~mm}, 5 \mu \mathrm{m}$ particle size) with a simple isocratic mobile phase composed of acetonitrile and phosphate buffer at a $\mathrm{pH}$ of 6.0 with the ratio of 30 and 70 and flow rate of $1 \mathrm{ml} / \mathrm{min}$.

Sitagliptin UV spectrum was determined by PDA plus detector which showed that the peak purity value is 1.03 and the maximum absorption wavelength was found at $268 \mathrm{~nm}$ (Figure 3). The analyte eluted at 4.607 min with a total analytical run time of $10 \mathrm{~min}$.

Specificity. From figure 3, the UHPLC chromatogram for the blank, standard and sample separately revealed that there was no interfering peak with sitagliptin.

System suitability test. After six replicate injection of the nominal concentration $(50 \mu \mathrm{g} / \mathrm{ml})$ the $\%$ RSD of obtained data such as peak area, theoretical plate, tailing factor and retention time were not more than $2 \%$ (Table 2$)^{27}$

Table 2. Results of system suitability test.

\begin{tabular}{ll}
\hline Parameters & Value (Mean $\pm \%$ RSD) \\
\hline Peak area & $2,116,867 \pm 0.41$ \\
Theoretical plate & $6938 \pm 0.35$ \\
Tailing factor & $1.025 \pm 0.14$ \\
Retention time & $4.607 \pm 0.12 \mathrm{~min}$ \\
\hline
\end{tabular}

Linearity. The regression curve was constructed by linear regression and its mathematical expression was $y=42127 x+2099.3$, where $y$ is the peak area and $\mathrm{x}$ is the concentration of sitagliptin (Figure 4). Linearity parameters of sitagliptin are described in table 3.

Table 3. Linearity parameters of sitagliptin.

\begin{tabular}{ll}
\hline Linearity Parameters & Obtained value \\
\hline Regression Correlation Coefficient & 0.999 \\
Y-intercept & 2099 \\
Slope of Regression Line & 42127 \\
LOD & $0.06 \mu \mathrm{g} / \mathrm{ml}$ \\
LOQ & $0.225 \mu \mathrm{g} / \mathrm{ml}$ \\
\hline
\end{tabular}



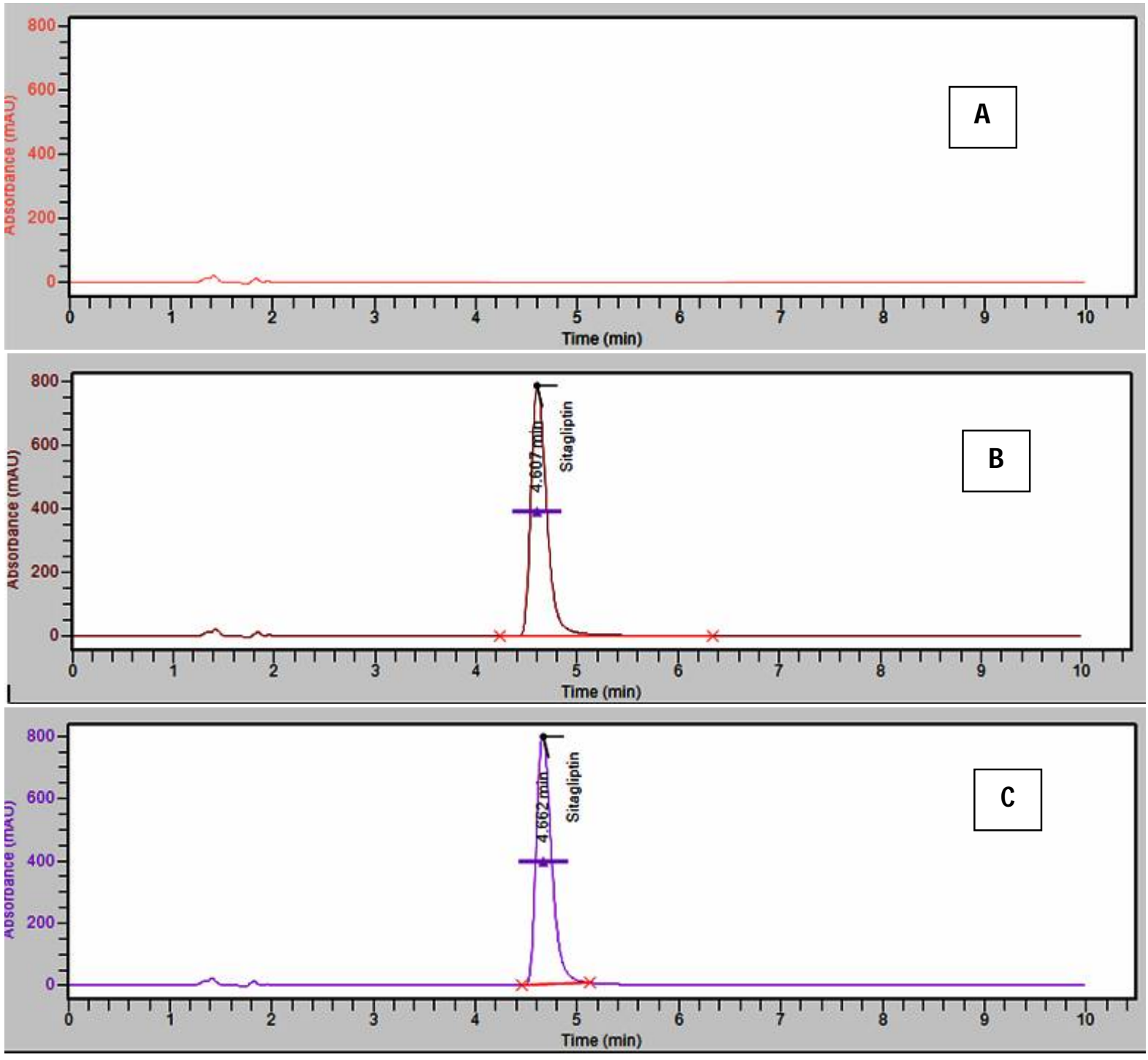

Figure 2. UHPLC chromatogram of blank (A), sitagliptin standard solution (B) and sample solution (C).

Table 4. Inter-day and intra-day precision for sitagliptin.

\begin{tabular}{|c|c|c|c|c|c|c|c|}
\hline \multirow{3}{*}{$\begin{array}{l}\text { Inter- } \\
\text { day }\end{array}$} & Time (hr) & 0 & 1 & 2 & 4 & 8 & 12 \\
\hline & Assay (\%) & $99.56 \pm 0.06$ & $99.25 \pm 0.23$ & $99.03 \pm 0.28$ & $99.45 \pm 0.41$ & $99.88 \pm 0.55$ & $99.60 \pm 0.63$ \\
\hline & Mean \pm SD & & & & & & \\
\hline \multirow{3}{*}{$\begin{array}{l}\text { Intra- } \\
\text { day }\end{array}$} & Day & 1 & 2 & 3 & 4 & 5 & 6 \\
\hline & Assay (\%) & $99.85 \pm 0.33$ & $99.55 \pm 0.25$ & $99.06 \pm 0.39$ & $98.87 \pm 0.74$ & $98.54 \pm 0.24$ & $98.24 \pm 0.44$ \\
\hline & Mean \pm SD & & & & & & \\
\hline
\end{tabular}

Accuracy. The result of recovery study (Table 5) showed that the method was found accurate and the $\%$ RSD was not more than $2 \%$.
Robustness. The variation for robustness study performed by changing flow rate $( \pm 0.2 \mathrm{ml} / \mathrm{min})$, column temperature $\left( \pm 3^{\circ} \mathrm{C}\right)$, composition of mobile 
phase ( $\pm 5 \%$ of acetonitrile) resulted in SD and \% RSD NMT 2\%, which indicated good and satisfactory robustness of the proposed method (Table 6).

The developed method could elute the drug molecule at 4.607 minute which is shorter than the method described by Prasad et al. ${ }^{19}$, S. Patil et al. ${ }^{21}$, Chellu et $a .^{22}$ which indicated the rapid
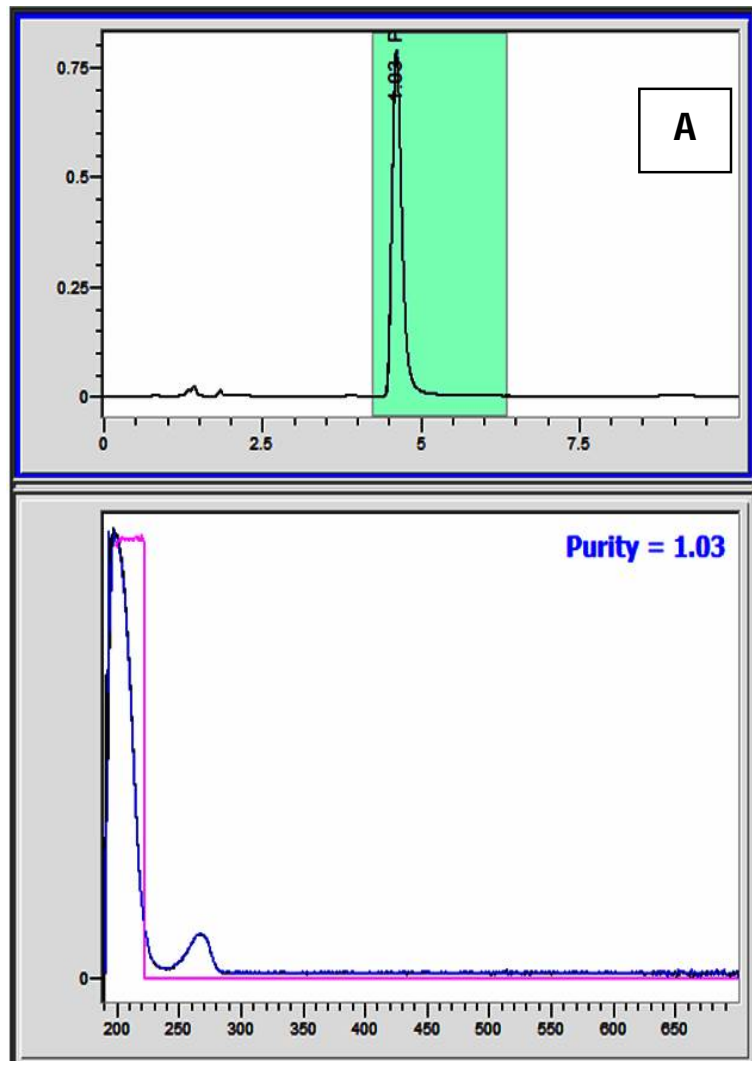

Figure 3. Peak purity (A) and maximum wavelength, $268 \mathrm{~nm}$ (B) of sitagliptin

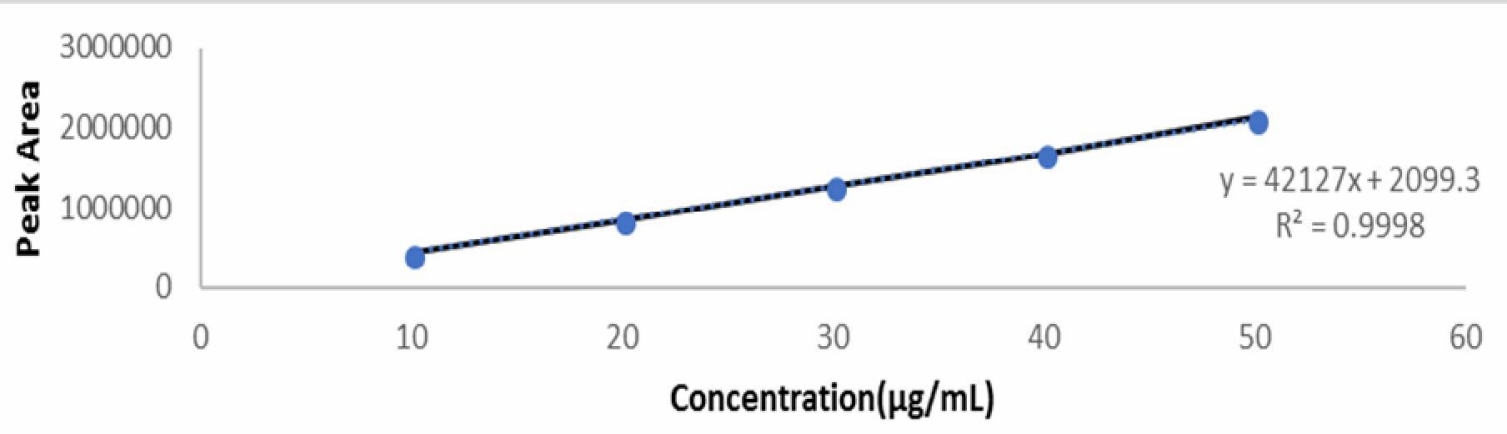

Figure 4. Linearity curve of sitagliptin.

quantification capacity. In addition, the method was found to be free from cumbersome mobile phase composition with additional advantages of less consumption of organic solvents that of reported methods of Konari and Jane ${ }^{5}$, Shyamala et al. ${ }^{16}$, Bhende et al. ${ }^{17}$, Rao et al. ${ }^{18}$ and Patil et al. ${ }^{21}$
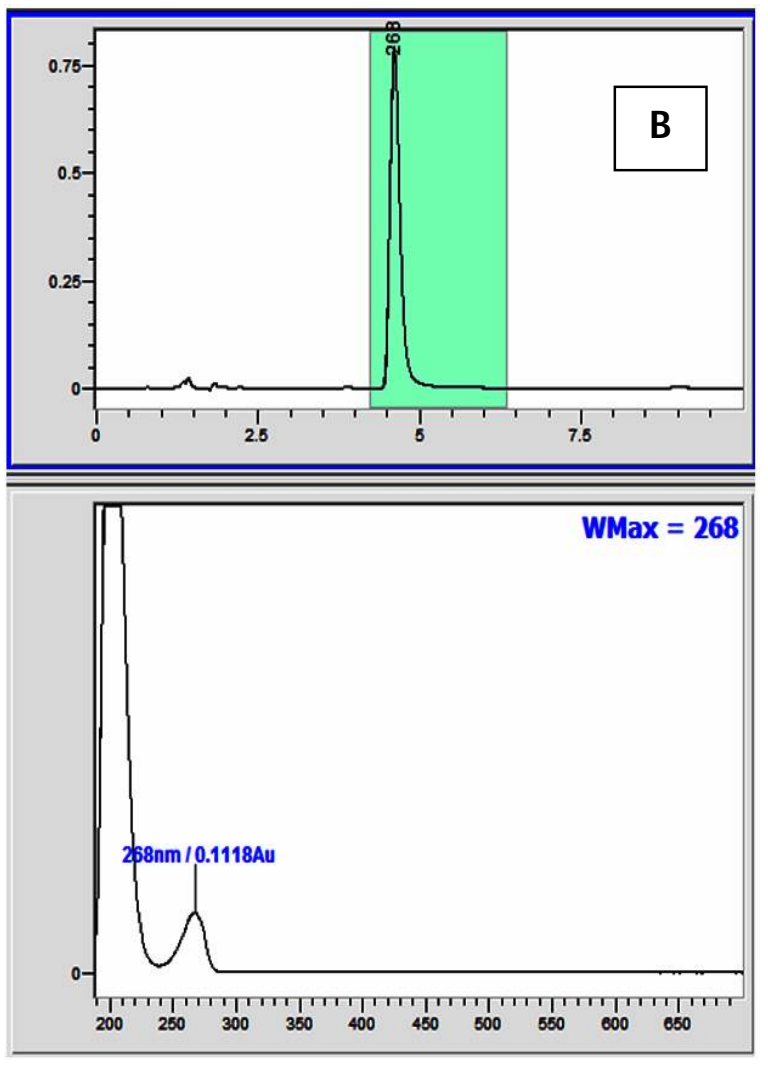
Table 5. Recovery study for method validation of sitagliptin.

\begin{tabular}{lll}
\hline Sl\# & Level $(\%)$ & \% Recovered $\pm \mathrm{SD}^{*}$ \\
\hline 1 & 80 & $99.70 \pm 0.05$ \\
2 & 100 & $98.50 \pm 0.03$ \\
3 & 120 & $99.43 \pm 0.09$ \\
\hline \multicolumn{3}{l}{ *Mean of triplicate determinations. }
\end{tabular}

Table 6. Robustness study for method validation of sitagliptin.

\begin{tabular}{llll}
\hline Parameters & Variations & $\begin{array}{l}\text { Amount } \\
\text { Added } \\
(\mu \mathrm{g} / \mathrm{ml})\end{array}$ & $\begin{array}{l}\text { Amount } \\
\text { Detected } \\
(\mu \mathrm{g} / \mathrm{ml}) \\
\left(\mathrm{Mean} \pm \mathrm{SD}^{*}\right)\end{array}$ \\
\hline $\begin{array}{l}\text { Flow rate } \\
(\mathrm{ml} / \mathrm{min})\end{array}$ & 1 & 50 & $50.12 \pm 0.09$ \\
& 1.2 & 50 & $49.95 \pm 0.16$ \\
$\begin{array}{l}\text { Column } \\
\text { temperature }\end{array}$ & 22 & 50 & $50.04 \pm 0.24$ \\
$\begin{array}{l}\left.{ }^{\circ} \mathrm{C}\right) \\
\begin{array}{l}\text { Mobile phase } \\
\text { composition }\end{array}\end{array}$ & 25 & 50 & $50.14 \pm 0.15$ \\
$\begin{array}{l}\text { (Acetonitrile } \\
\%)\end{array}$ & 30 & 50 & $50.86 \pm 0.19$ \\
\hline
\end{tabular}

*Mean of triplicate determinations

\section{CONCLUSION}

In pharmaceutical market, the demand of DPP-4 inhibitor products is growing. So, it was highly necessary to develop an easy and simple technique to quantitate the drug in the dosage forms. The reported method is time-saving, rapid, selective, linear, precise, accurate and robust. Thus, the method seems to be appropriate for the quality control in pharmaceutical industries as well as for drug substances quantitation in biological fluid during in vivo studies.

\section{ACKNOWLEDGEMENT}

This research work has been supported by Higher Education Quality Enhancement Project (HEQEP), AIF, Round-III, Window-2, CP-3245, Award No. 26, University Grants Commission (UGC), Bangladesh.

\section{REFERENCES}

1. Khan, G., Sahu, D., Agrawal, Y.P., Sabarwal, N., Jain, A. and Gupta, A.K. 2011. Simultaneous estimation of metformin and sitagliptin in tablet dosage form. Asian J. Biochem. Pharm. Res. 2, 352-358.

2. Herman, G.A., Stevens, C., Dyck, V.K., Bergman, A., Yi, B. and De Smet, M. 2005. Pharmacokinetics and pharmacodynamics of sitagliptin, an inhibitor of dipeptidyl peptidase IV, in healthy subjects: Results from two randomized, double-blind, placebo-controlled studies with single oral doses. Clin. Pharmacol. Ther. 78, 675-688.

3. Dicker, D. 2011. DPP-4 inhibitors. Diabetes Care 34, 276-278.

4. World Health Organization. 2016. Global Report on Diabetes. p. 6. http://www.who.int/diabetes/global-report/en/ Accessed on 25 February, 2018.

5. Konari, S.N. and Jane, T.J. 2015. Stability indicating validated RP-HPLC technique for the analysis of multicomponent anti-diabetic drug combos in pharmaceutical dosage forms. Karbala Int. J. Modern Sci. 1, 39-48.

6. Sultana, S., Kumar, U., Hossain, M.S., Lira, D.N. and Rouf, A.S.S. 2017. QbD approach for the development and validation of RP-UHPLC method for quantitation of vildagliptin. Dhaka Univ. J. Pharm. Sci. 16, 107-117.

7. Sultana, S., Lira, D.N., Hossain, M.S. and Rouf, A.S.S. 2015. Optimized and validated RP-HPLC method for the determination of esomeprazole magnesium in pharmaceutical formulation. Dhaka Univ. J. Pharm. Sci. 14, 225-232.

8. Sultana, S., Ahammad, T., Islam, M.A. and Rouf, A.S.S. 2013. RP-HPLC method development and validation for nitazoxanide in powder for suspension dosage form. Int. J. Pharm. Sci. Res. 4, 301-305.

9. Alam, M.M., Hossain, M.S., Bhadra, S., Kumar, U. and Rouf, A.S.S. 2017. Development and validation of RP-HPLC method for quantitation of clarithromycin in matrix tablet dosage form. Dhaka Univ. J. Pharm. Sci. 16, 69-75.

10. Hossain, M.S., Islam, M.S., Bhadra, S. and Rouf, A.S.S. 2016. Screening of caffeine, preservatives and antioxidants in dairy products available in Bangladesh using an RP-HPLC method. Int. J. Food Contam. 3, 11.

11. Islam, M.S., Hossain, M.S., Bhadra, S. and Rouf, A.S.S. 2016. Simultaneous determination of caffeine, preservatives and antioxidants in energy-and soft-drinks commercially available in Bangladesh. Dhaka Univ. J. Pharm. Sci. 15, 97 108.

12. Hossain, M.F., Bhadra, S., Kumar, U. and Rouf, A.S.S. 2013. The ICH guidance in practice: Stress degradation studies on aceclofenac and development of a validated stabilityindicating reversed-phase HPLC assay in tablet dosage form. Der. Pharma. Chem. 5, 131-46. 
13. El-Bagary, R.I., Elkady, E.F. and Ayoub, B.M. 2011. Spectroflourometric and spectrophotometric methods for the determination of sitagliptin in binary mixture with metformin and ternary mixture with metformin and sitagliptin alkaline degradation product. Int. J. Biomed. Sci. 7, 62-69.

14. Jain, P., Chaudhary, A., Desai, B., Patel, S., Patel, S. and Shimpi, H. 2011. Development and validation of first order derivative UV spectrophotometric method for determination of sitagliptin in bulk and in formulation. Int. J. Drug Dev. Res. 3, 194-199.

15. Bala, S.C. and Prameela, R.A. 2010. Development and validation of spectrophotometric method for the determination of DPP4 inhibitor sitagliptin, in its pharmaceutical dosage forms. Int. J. Pharm. Sci. 2, 138-142.

16. Shyamala, M., Mohideen, S., Satyanarayana, T., Narasimha, R.C.H., Suresh, K.P. and Swetha, K. 2011. Validated RPHPLC for simultaneous estimation of sitagliptin phosphate and metformin hydrochloride in tablet dosage form. Am. J. PharmTech Res. 1, 93-101.

17. Bhende, S.D., Balaram, V.M., Abbulu, K., Divya, S.M., Shravanthi, V., Karuna, K.J. and Shayamala, T. 2012. RPHPLC method for the simultaneous estimation of sitagliptin phosphate and metformin hydrochloride in combined tablet dosage forms. Orient. J. Chem. 28, 463.

18. Gangrade, D. and Sharma, A. 2015. Validated RP-HPLC method for simultaneous estimation of metformin hydrochloride and sitagliptin phosphate in bulk drug and pharmaceutical dosage form. Der Pharm. Sin. 6, 6-10.

19. Prasad, P.B., Satyanarayana, K. and Krishnamohan, G. 2014. Development and validation of a method for simultaneous determination of metformin hydrochloride and sitagliptin phosphate in a formulation by RP-HPLC. Am. J. Anal. Chem. 5, 737-742.
20. Lavanya, R., Yunoos, M. and Pradesh, A. 2013. Development and validation of RP-HPLC method for the estimation of sitagliptin phosphate in bulk and its tablet dosage form. J. Adv. Pharm. Edu. Res. 3, 475- 479.

21. Patil, S., Ramesh, B., Hareesh, A.R., Patil, K. and Dhokane, A. 2010. Development and validation of RP-HPLC method for the estimation of sitagliptin phosphate in tablet dosage form. Asian J. Res. Chem. 3, 653-655.

22. Chellu, S.N., Malleswararao, M. and Suryanarayana, V. 2012. Simultaneous determination of sitagliptin phosphate monohydrate and metformin hydrochloride in tablets by a validated UPLC method. Sci. Pharm. 80, 139-152.

23. Swales, J.G., Gallagher, R.T., Denn, M. and Peter, R.M. 2011. Simultaneous quantitation of metformin and sitagliptin from mouse and human dried blood spots using laser diode thermal desorption tandem mass spectrometry. J. Pharm. Biomed. Anal. 55, 554-551.

24. Zeng, W., Musson, D.G., Fisher, A.L., Michael, L.S., Schwartz, J.S. and Wang, A.Q. 2008. Determination of sitagliptin in human urine and hemodialysate using turbulent flow online extraction and tandem mass spectrometry. $J$. Pharm. Biomed. Anal. 46, 534-542.

25. Sohajda, T., Hui, W.H., Zeng, L.L., Li, H., Szente, L. and Noszal, B. 2011. Evaluation of the interaction between sitagliptin and cyclodextrin derivatives by capillary electrophoresis and nuclear magnetic resonance spectroscopy. Electrophoresis 32, 2648-2654.

26. International Conference on Harmonization. 2005. Validation of Analytical Procedures: Text and Methodology, Q2 (R1). IFPMA, Geneva, Switzerland.

27. USP 27/NF 22, 2003. United States Pharmacopoeial Convention, Rockville, Maryland, USA, p. 2281. 